\title{
Essential Amino Acid
}

National Cancer Institute

\section{Source}

National Cancer Institute. Essential Amino Acid. NCI Thesaurus. Code C29595.

Refer to those amino acids that can not be synthesized in the body and can only be obtained through food supply. 